Gout

\section{Gout, diuretics and the kidney}

\section{E Pascual, M Perdiguero}

\section{Occurrence of gout may depend on the condition for which diuretics are prescribed rather than resulting from the drugs themselves}

G out is a monosodium urate crystal deposition disease. Formation of the crystals requires high serum uric acid levels; the local factors responsible for their predilection for the joints are only started to be grasped. ${ }^{12}$ Steady serum urate levels result from the balance between its production and excretion; hyperuricaemia results when formation is increased or difficulties in (mostly) renal excretion occur. In humans, urate is the final breakdown product of purine nucleotides, constituents of cellular energy stores such as ATP, and of DNA and RNA both internal or, to a lesser extent, ingested.

Increased urate formation is the cause of hyperuricaemia and gout in some well defined enzymatic defects, and also occurs as a consequence of increased destruction of cells in some malignancies, polycythaemia vera or some haemolytic anaemias. Patients with increased production of urate are classified as overproducers, and detection of an increased amount of excreted urate is considered to be a good method of detecting the few patients whose gout results either from enzymatic defectswhich are partial in the adult-or a tumour or other condition with a rapid cellular turnover. ${ }^{3}$

Two thirds of urate excretion occurs at the kidney, the remainder being excreted by the gut. In an estimated 85-90\% cases, gout results from poor renal disposal of urate. Gouty patients with normal or low excretion of uric acid (underexcretors) may be candidates for treatment with uricosuric drugs with little risk of urinary calculi. Measurement of the amount of excreted urate has also been recommended to identify these patients.

Measurement of the amount of excreted uric acid has been considered to have clinical implications. However, although on most occasions hyperuricaemia results from poor urate clearance in otherwise normal kidneys, its calculation appears to have little use for patient management and has received little attention in the clinical setting. But this measurement is often informative, explaining why many gouty patients develop their disease.

Understanding the renal handling of urate has been hampered by the differences in transport among species. Humans-along with higher primates ${ }^{4}$ - differ from other mammals because they do not possess uricase, which further degrades poorly soluble uric acid into the soluble allantoin, which is easily disposed of, and also their transport of urate across renal tubular cells is a complex bidirectional process. In humans, only $5-10 \%$ of the filtered urate is finally excreted, the largest part being reabsorbed at the tubules, ${ }^{5}$ largely at the proximal convoluted tubule. Earlier studies had suggested that the urate is almost fully reabsorbed and that the urate excreted by the kidney is the result of tubular secretion, but more recent data suggest that secretion plays little part, and that excreted urate largely represents the filtered urate which escapes reabsorption. ${ }^{6}$

\section{"Urate transport through tubular cells depends on four proteins: UAT, OAT1, OAT3, URAT1"}

Urate is poorly soluble, and has to be transported across cell membranes. We have recently gained insight into the mechanisms of urate transport through tubular cells with the identification of four proteins which act as urate transporters at that level: UAT (urate transporter/channel), two members of the of the family of organic anion transporters (OATl and OAT3) related to the tubular secretion of urate, and the main protein responsible for tubular reabsorption of urate (URAT1), located at the apical membrane of the proximal tubular cells. $^{78}$

Creatinine clearance provides a close estimate of glomerular filtrate, and normally approaches $125 \mathrm{ml} / \mathrm{min}$. The normal values of urate clearance are about $9 \mathrm{ml} / \mathrm{min}$; the large difference between both clearances is due to the very large amount of the filtered urate which is absorbed at the tubules. The fractional excretion of urate is the relation between urate and creatinine clearances, and is reported as a percentage: the normal fractional excretion of urate approaches $7-12 \%$, which represents the percentage of the filtered urate which is finally excreted. The fractional excretion of urate can be simply calculated on simultaneous spot urine and blood samples (urine $\mathrm{UA} \times$ serum $\mathrm{Cr}$ / serum UA $\times$ urine $\mathrm{Cr}),{ }^{9}$ avoiding the cumbersome $24 \mathrm{~h}$ urine collections which tend to be inaccurate. ${ }^{10}$

Fractional excretion of urate helps us to understand the normal or altered urate levels in a number of circumstances. Thus the lower serum urate levels of women, which are at least partially explained by their higher fractional excretion of urate ${ }^{11}$ and by the increase in urate levels from prepubertal to pubertal girls, coincides with a decrease of their fractional excretion of urate. ${ }^{12}$ By contrast, the lower uricaemia which gouty patients present during gouty attacks is due to a higher fractional excretion of urate, ${ }^{13}$ and the very low uricaemia which may accompany jaundice, some solid haematological tumours, diabetes or intracranial diseases, results from a very high fractional excretion of urate leading to inappropriate uricosuria. ${ }^{14}$

Difficulty in renal urate excretion is also responsible for hyperuricaemia and gout, These are associated with a number of common situations, such as the metabolic syndrome ${ }^{15}$ - which is correctable by changing to a low caloric $\operatorname{diet}^{16}$ essential hypertension, ${ }^{17}$ decompensated heart failure, ${ }^{18}$ saturnine gout — which is correctable by lead chelation ${ }^{19}$-alcohol consumption. Hyperuricaemia and gout also occur as a result of the ingestion of different drugs such as ciclosporin ${ }^{20}$ or low dose aspirin, ${ }^{21}$ and of which, diuretics are the most widely prescribed. A low fractional excretion of urate has also been found in patients with high $24 \mathrm{~h}$ uric acid excretion. ${ }^{9}$ Establishing how the kidney handles urate by calculating the fractional excretion of urate, or the urate clearance, may be of little use in choosing a hypouricaemic drug, but can help us to understand the reason for a patient's hyperuricaemia.

Hyperuricaemia is a widely publicised consequence of diuretic treatment, such that in the current guidelines on the management of hypertension, having gout is considered as a contraindication for the administration of diuretics. ${ }^{22} 23$ Diuretics induce hyperuricaemia by increasing urate reabsorption, though the exact mechanism has not been elucidated. It has been noted that hyperuricaemia occurs when diuretics produce sufficient salt and water loss as to result in volume contraction; this 
stimulates solute reabsorption at the proximal tubule, ${ }^{24} 25$ and this effect is corrected by administration of the lost fluid. ${ }^{26}$

Different diuretics are likely to have different effects on the renal handling of urate, but this has not been critically ascertained; patients receiving more powerful loop diuretics have a higher risk of developing gout than those receiving the weaker thiazides. ${ }^{27}$ Interestingly, bumetanide has been found to have uricosuric properties. ${ }^{28}$

\section{"Renal handling of urate depends on the type of diuretic used"}

In this issue of the Annals, Janssens et al report that in their gouty patients who received diuretics their gout related to the condition for which the diuretics were prescribed, rather than resulting from the drugs themselves. ${ }^{29}$ These data are not surprising, because as already noted, diuretics are generally prescribed for situations such as heart failure or hypertension, which are by themselves associated with poor clearance of urate. $^{171830}$ Their paper is welcome, because most of the information on hyperuricaemia and gout seen after the introduction of diuretics to patients who already have these predisposing conditions is drawn from observational data and has received little critical attention. ${ }^{31}$ Diuretics are often prescribed to patients with conditions which predispose to poor urate disposal. Their action on urate disposal by the kidney may simply be additive, but it might also result in modification of the renal disposal of urate of a different magnitude, and in light of the frequent use of diuretics in severe diseases, this is worth ascertaining.

As we learn to what extent hyperuricaemia associated with diuretics is due to a direct and specific action of these drugs on the tubular wall or whether they act more generally by reducing the vascular volumes, this will undoubtedly increase our understanding of the association. To understand different clinical situations it appears important to determine how the kidney handles urate, either by calculating the fractional excretion of urate, or the urate clearance. On those occasions in which there is coincidence of more than one factor associated with a reduced urate excretion, these data-along with the serum uric acid measurement-may allow us to gauge better the relative weight of the different factors, such as for instance hypertension and a diuretic prescribed for its control. Also, these data may help us in decisions related to the treatment of individual patients.

Ann Rheum Dis 2006;65:981-982.

doi: 10.1136/ard.2005.049023

\section{Authors' affiliations}

E Pascual, Hospital General Universitario de Alicante, Universidad Miguel Hernandez,

Alicante, Spain

M Perdiguero, Nephrology section, Hospital

General Universitario de Alicante

Correspondence to: Professor E Pascual,

Sección de Reumatología, Hospital General Universitario de Alicante, Maestro Alonso 109, 03010 Alicante, Spain; pascual_eli@gra.es

Accepted 13 March 2006

\section{REFERENCES}

1 Simkin PA. The pathogenesis of podagra. Ann Intern Med 1977;86:230-3.

2 Pascual E, Ordóñez S. Orderly arrayed deposit of urate crystals in gout suggest epitaxial formation. Ann Rheum Dis 1998;57:255.

3 Simkin PA. When, why, and how should we quantify the excretion rate of urinary uric acid? J Rheumatol 2001;28:1207-10.

4 Watanabe S, Kang DH, Feng L, Nakagawa T, Kanellis J, Lan $\mathrm{H}$, et al. Uric acid, hominoid evolution, and the pathogenesis of salt-sensitivity. 2002;40:355-60

5 Maesaka JK, Fishbane S. Regulation of renal urate excretion: a critical review. Am J Kidney Dis 1998;32:917-33.

6 Roch-Ramel F, Guisan B. Renal transport of urate in humans. News Physiol Sci 1999;14:80-4.

7 Hediger MA, Johnson RJ, Miyazaki H, Endou H. Molecular physiology of urate transport. Physiology (Bethesda) 2005;20:125-33.

8 Enomoto A, Endou $\mathrm{H}$. Roles of organic anion transporters (OATs) and a urate transporter (URAT1) in the pathophysiology of human disease. Clin Exp Nephrol 2005;9:195-205.

9 Perez-Ruiz F, Calabozo M, García-Erauskin G, Ruibal A, Herrero Beites AM. Renal underexcretion of uric acid is present in patients with apparent high urinary uric acid output. Arthritis Rheum 2002:47:610-13.

10 Simkin PA, Hoover PL, Paxson CS, Wilson WF Uric acid excretion: quantitative assessment from spot, midmorning serum and urine samples. Ann Intern Med 1979;91:44-7.

11 Quarantino CP, Di Sciacio N, Rucci C, Ciaglia P, Giacomello $A$. The normal range of serum urate levels and of fractional urate excretion. Adv Exp Med Biol 1994:370:91-3.

12 Garbagnati E, Boschetti M. Uric acid homeostasis in lean and obese girls during pubertal development. Metabolism 1994;43:819-21.

13 Urano W, Yamanaka H, Tsutani H, Nakajima H, Matsuda Y, Taniguchi A, et al. The inflammatory process in the mechanism of decreased serum uric acid concentrations during acute gouty arthritis. J Rheumatol 2002;29:1950-3.

14 Bairaktari ET, Kakafika Al, Pritsivelis N, Hatzidimou KG, Tsianos EV, Seferiadis KI, et al. Hypouricemia in individuals admitted to an inpatient hospital-based facility. Am J Kidney Dis 2003:41:1225-32.

15 Facchini F, Chen Y-D, Hollenbeck CB, Reaven GM. Relationship between resistance to insulin-mediated glucose uptake, urinary uric acid clearance, and plasma uric acid concentration. JAMA 1991;266:3008-11.

16 Tinahones JF, Pérez Lindón G, C-Soriguer FJ, Pareja A, Sánchez Guijo P, Collantes E. Dietary alterations in plasma very low density lipoprotein levels modify renal excretion of urates in hyperuricemic-hypertriglyceridemic patients. J Clin Endocrinol Metab 1997;82:1 188-91.

17 Tykarski A. Evaluation of renal handling of uric acid in essential hypertension: hyperuricemia related to decreased urate secretion. Nephron, 1991;59:364-8.

18 Ochiai ME, Barreto ACP, Oliveira MT, Munhoz RT, Morgado PC, Ramires JAF. Uric acid renal excretion and renal insufficiency in decompensated severe heart failure. Eur J Heart Fail 2005;7:468-74.

19 Lin JL, Yu CC, Lin-Tan DT, Ho HH. Lead chelation therapy and urate excretion in patients with chronic renal diseases and gout. Kidney Int 2001;60:266-71.

20 Lin HY, Rocher LL, McQuilan MA, Schmatz S, Palella TD, Fox IH. Cyclosporine induced hyperuricemia and gout. N Engl J Med 1989;321:287-92.

21 Caspi D, Lubart E, Graff E, Habot B, Yaron M Segal R. The effect of mini-dose aspirin on renal function and uric acid handling in elderly patients. Arthritis Rheum 2000;43:103-8.

22 WHO. World health organisation-international society of hypertension (WHO/ISH) hypertension guidelines. Clin Exp Hypertens 2004; 26:747-52.

23 European Society of Hypertension-European Society of Cardiology Guidelines Committee. European Society of Hypertension-European Society of Cardiology guidelines for the management of arterial hypertension. $J$ Hypertens 2003;21:1011-53.

24 Steele TH, Oppenheimer S. Factors affecting urate excretion following diuretic administration in man. Am J Med 1969;47:564-74.

25 Suki WN, Hull AR, Rector FC, Seldin DW. Mechanism of the effect of the thiazide diuretics on calcium and uric acid. $J$ Clin Invest 1967;46:1121.

26 Khan AM. Effect of diuretics on the renal handling of urate. Semin Nephrol 1988:8:305.

27 Waller PC, Ramsay LE. Predicting acute gout in diuretic-treated hypertensive patients. J Hum Hypertens 1989;3:457-61.

28 Hopkinson N, Doherty M. In patients with chronic cardiac failure who have diuretic induced gout are certain diuretics less prone at causing problems? Br J Rheumatol 1991;30:225.

29 Janssens HJEM, van de Lisdonk EH, Janssens M, van den Hoogen HJM, Verbeek ALM. Gout, not induced by diuretics? A case-control study from primary care. Ann Rheum Dis 2006;65:1080-3

30 Scott JT, Higgens CS. Diuretic induced gout: a multifactorial condition. Ann Rheum Dis 1992:51:259-61.

31 Choi HK, Atkinson K, Karlson EW, Curhan G. Obesity, weight change, hypertension, diuretic use, and risk of gout in men: the health professionals follow-up study. Arch Intern Med 2005; 165:742-8. 